\title{
APPLICATION OF IMPRINT CYTOLOGY IN INTERPRETATION OF ESOPHAGEAL BIOPSIES.
}

Asha Mahadevappa 1, Divya Vijayanarasimha², Manjunath GV3, Sunila R4.

1. Associate professor, Department of Pathology, JSS Medical College, Mysore.

2. Post Graduate, Department of Pathology, JSS Medical College, Mysore.

3. Professor, Department of Pathology, JSS Medical College, Mysore.

4. Professor, Department of Pathology, JSS Medical College, Mysore.

\section{CORRESPONDING AUTHOR}

\section{Dr Divya $\mathrm{V}$,} $17,2^{\text {nd }}$ Main,

Kamakshi Hospital road,

Opp. Rotary West School, Kuvempunagar,

Mysore 570023.

Email-divyamala@ymail.com

\section{HOW TO CITE THIS ARTICLE:}

Asha Mahadevappa, Divya Vijayanarasimha, Manjunath GV, Sunila R. "Application of imprint cytology in interpretation of esophageal biopsies." Journal of Evolution of Medical and Dental Sciences 2013; Vol2, Issue 24, June 17; Page: 4350-4357.

ABSTRACT: Early detection is crucial in diagnosis and treatment of upper gastro intestinal (GI) lesions. GI malignancy may be suspected on clinical grounds and by imaging techniques; however cytohistologic evaluation of lesional tissue is necessary to provide a definitive diagnosis before treatment is initiated. Lesions of esophagus constitute a major part of upper GI pathology encountered in practice and patients present with complaints of dysphagia or reflux. Cytological diagnostic techniques including brush and touch imprint cytology are gaining popularity. The biopsy forceps can obtain material deeper than the brush and touch imprints made from them provide more information, besides providing material for histological examination. The present study provides an insight into application of imprint cytology in esophageal endoscopic biopsies. The results of imprint cytology were correlated with standard histopathology. In this study of 45 biopsies; sensitivity, specificity and diagnostic accuracy of 94.3\%, 100\%, 95.6\% were recorded respectively which are higher than those of brush cytology recorded in various studies. Methods of reporting GI cytology have also been discussed besides discussing the pitfalls and limitations. Awareness of pitfalls will improve diagnostic accuracy and prevent false-positive and negative diagnosis.

INTRODUCTION: Gastrointestinal (GI) endoscopy is an essential part of evaluation of GI pathology. The simplicity, convenience and safety of modern endoscopy has resulted in major advances in management lesions of GIT. 1

Various neoplastic and non neoplastic lesions of esophagus constitute a major part of upper GI pathology encountered in practice. Biopsies taken from these lesions help in accurate diagnosis in most cases. In diagnosis of esophageal neoplasms, histopathology (HPE) is considered gold standard, 


\section{ORIGINAL ARTICLE}

but is time - consuming in comparison with cytology. Most gastroenterologists and patients would like to have an immediate opinion regarding the adequacy of the biopsy and also about the benign or malignant nature of the lesion. Biopsy touch imprint cytology (IC) is a simple, inexpensive and rapid diagnostic method, though rarely practiced.

Thus a study to show correlation of results of IC and standard HPE of esophageal lesions will be helpful and may allow the procedure to be performed more often.

METHODS: 45 patients with symptoms suggestive of esophageal pathology and who underwent endoscopic biopsies were included in the study. Biopsies with inadequate material and slides showing crush artifacts were excluded from the study.

In endoscopically suspected lesions, 4 - 6 biopsies were taken from the lesion. Touch imprints of the biopsies were made from fresh biopsy specimen by gently rolling the tissue on glass slides using needles and applying gentle pressure at intervals. The imprint smears were immediately fixed in 95\% alcohol. A minimum of four imprint slides made for each case and were stained with Haematoxylin and Eosin and Papanicolaou, stains. The same biopsy tissue was put in $10 \%$ formalin for fixation. Routine histopathological processing was done. Sections were cut at $5 \mu \mathrm{m}$ thickness and stained with Haematoxylin and Eosin. The slides were interpreted and analyzed.

On cytology, lesions were categorized as

Unsatisfactory: When cellularity was low or when cells were obscured by blood/ mucus

Negative for malignancy: When cells showed no atypia. Mild atypia in the presence of inflammatory cells was considered as negative for malignancy

Suspicious of malignancy: When smears showed borderline atypia in the presence of low cellularity.

Positive for malignancy: When the following features were present: hypercellularity, irregular and abnormal shaped cells, nuclear irregularity, macro nucleoli, high N:C ratio, signet ring cells, tumor cannibalism. Sub-typing of tumor was done wherever possible.

On histopathology, lesions were categorized as

Negative for any pathology

Inflammatory

Dysplasia

Positive for malignancy

The results of IC were then correlated with those of HPE.

RESULTS: An observational study with 45 patients was undertaken to study the spectrum of pathological findings in endoscopic biopsies of esophagus and to correlate the results of IC made from them with HPE. The study included 11(24.4\%) non- neoplastic and 34(75.6\%) neoplastic lesions.

Neoplastic lesions of esophagus were most often found in the lower $1 / 3^{\text {rd }}$ of esophagus (55.6\%), followed by middle $1 / 3^{\text {rd }}(35.6 \%)$ and upper $1 / 3^{\text {rd }}(8.8 \%)$. Males in $5^{\text {th }}$ and $6^{\text {th }}$ decades of life were affected most commonly. The youngest patient was a 24 year- old female with esophageal squamous cell carcinoma 
Dysphagia was the most common indication for endoscopic evaluation in esophageal lesions. Malignancies presented as proliferative (58.2\%) or ulceroproliferative (29.4\%) lesions in most cases. Two cases were evaluated suspecting Barrett esophagus on endoscopy.

DISTRIBUTION OF IMPRINT CYTOLOGY DIAGNOSIS: Imprint smears were categorized as unsatisfactory, negative for malignancy, suspicious of and positive for malignancy. One case was reported as unsatisfactory due to insufficient cellularity. (Table 1)

DISTRIBUTION OF HPE DIAGNOSIS: Lesion were categorized as neoplastic and non- neoplastic on HPE, which were then sub-classified as normal, inflammatory and columnar lined mucosa under non neoplastic and squamous cell carcinoma, adenocarcinoma, poorly differentiated carcinoma, lymphoma and dysplasia under neoplastic.

No benign neoplasms were seen. Squamous cell carcinoma of esophagus (61.8\%), was the commonest neoplastic lesion. (Table 2)

CORRELATION OF FINDINGS OF IMPRINT CYTOLOGY WITH HPE REPORT: The sensitivity, specificity, positive predictive value, negative predictive value and diagnostic accuracy were 94.29, $100,100,83.33$ and $95.56 \%$ respectively. p value was calculated to be $<0.001$ applying Chi-square and Fisher Exact test.

\section{TABLE 1: Distribution of imprint cytology diagnosis}

\begin{tabular}{|l|l|l|}
\hline Imprint cytology report & No. of cases & \% \\
\hline Unsatisfactory & 01 & 2.2 \\
\hline Negative for malignancy & 12 & 26.7 \\
\hline Suspicious of malignancy & 06 & 13.3 \\
\hline Positive for malignancy & 26 & 57.8 \\
\hline Total & 45 & 100 \\
\hline
\end{tabular}

TABLE 2: Distribution of HPE diagnosis

\begin{tabular}{|c|l|l|}
\hline HPE report & No. of cases & $\mathbf{\%}$ \\
\hline Total non-neoplastic & $\mathbf{1 1}$ & $\mathbf{2 4 . 4}$ \\
\hline$\bullet \quad$ Inflammatory lesion & 04 & 36.3 \\
\hline$\bullet \quad$ Barrett esophagus & 01 & 9.1 \\
\hline$\bullet \quad$ Normal & 06 & 54.5 \\
\hline Total neoplastic & $\mathbf{3 4}$ & $\mathbf{7 5 . 6}$ \\
\hline$\bullet \quad$ Squamous cell carcinoma & 21 & 61.8 \\
\hline$\bullet \quad$ Adenocarcinoma & 01 & 2.9 \\
\hline$\bullet \quad$ Poorly differentiated carcinoma & 09 & 26.5 \\
\hline$\bullet \quad$ Lymphoma & 0 & 0 \\
\hline$\bullet \quad$ Dysplasia & 03 & 8.8 \\
\hline Total & $\mathbf{4 5}$ & $\mathbf{1 0 0}$ \\
\hline
\end{tabular}




\section{ORIGINAL ARTICLE}

DISCUSSION: Endoscopic evaluation of esophageal lesions plays a major role in their management and in follow up. Cytological techniques, depending on the tumor location and type may be employed for primary diagnosis, prognosis, and prediction of tumor behavior. ${ }^{2}$

Every attempt should be made to give as definitive a diagnosis as possible. In cases where a specific diagnosis cannot be rendered, a differential or broader category should be used and the reason for doing so should be reported. The absence of positivity for a malignant process does not exclude malignancy, as the sensitivity of the procedure is less than $100 \%$. Clinical and radiological correlation is essential with repeat sampling for sub-optimal samples or for additional ancillary testing. ${ }^{3}$

The cytomorphological evaluation of gastrointestinal malignancies is highly dependent on the expertise in procuring, processing and evaluating the cytological specimens. The presence of a pathologist in the endoscopy suite to perform immediate assessment results in an adequate specimen in 100 percent of cases, as compared with only $71 \%$ when a pathologist was not present. ${ }^{4}$

In the present study, the salient features were

\section{IMPRINT CYTOLOGY:}

- One case was reported as "unsatisfactory" due to low cellularity and areas of necrosis. On HPE, this case showed poorly differentiated carcinoma with sheets of undifferentiated cells along with fragments showing only necrosis.

- 12 cases were reported as "negative for malignancy" where normal appearing squamous cells without atypia, with or without inflammation were present. [Fig 1] Out of these six cases showed no pathology on HPE, four cases showed non- specific chronic inflammation, one case showed columnar metaplasia. One case showed poorly differentiated carcinoma.

- Six cases were reported as "suspicious for malignancy" where borderline atypia was seen in a smear with low cellularity in the absence of inflammation. Out of these, four were reported as malignant and two as dysplasia on HPE.

- 26 smears were labeled as "positive for malignancy". Most smears showed good cellularity. Squamous cell carcinoma was identified by presence of pleomorphic squamoid cells mostly in sheets. Orangeophilia could be demonstrated on Pap stain. [Fig 2a, b, c] Most cases showed tumor diathesis with necrosis and inflammatory cells. Corresponding HPE slides showed squamous cell carcinoma in 20, dysplasia in one and four cases showed poorly differentiated carcinoma. One case showed atypical columnar cells in groups on IC and was reported as positive for malignancy. The corresponding HPE slides showed adenocarcinoma.

\section{HISTOPATHOLOGY:}

11 non - neoplastic lesions were identified that included six cases showing normal histology.

- There were four cases of non- specific esophagitis, with no specific age predilection. All cases of esophagitis were reported in males in contrast to the study by Lu et al who reported a slight female predominance. 10

- One case of columnar lined mucosa was seen, out of two cases of endoscopically suspected Barrett esophagus. Though "no goblet no Barrett" was the rule, 11 the presence of columnar metaplasia along with endoscopy is considered sufficient for a diagnosis of Barrett esophagus. Non-goblet columnar epithelium in the distal esophagus also shows DNA content 


\section{ORIGINAL ARTICLE}

abnormalities at rates comparable to those of esophageal goblet cells indicating that esophageal cardiac- type epithelium may already be "intestinalized" despite the absence of morphologic goblet cell differentiation. ${ }^{12}$ The need to document the presence of intestinal metaplasia in esophageal biopsies to diagnose Barrett esophagus is debated. ${ }^{13}$ [Fig 3a, b]

- Out of 34 neoplastic lesions, squamous cell carcinoma was most common, followed by poorly differentiated carcinoma and adenocarcinoma. ${ }^{9}$ Though in the western world, incidence of squamous cell carcinoma is declining with increase in adenocarcinoma, squamous cell carcinoma of lower $1 / 3^{\text {rd }}$ esophagus is still commonest in South India .

- There were three cases (8.8\%) which showed high grade dysplasia where, in the absence of sufficient sub epithelial tissue, invasion could not be ruled out and repeat biopsy was suggested.

- Candida was noted in one case which showed poorly differentiated carcinoma. Candida has been reported in $27 \%$ of malignancy cases in one series. ${ }^{14}$ [Fig 4 ]

CORRELATIONي Sensitivity of IC compared to standard HPE was 94.12\%, specificity $100 \%$, positive predictive value (PPV) was 100\%, negative predictive value (NPV) $84.62 \%$ and the diagnostic accuracy (DA) was 95.56\%, which correlated with results of Sharma et al who reported (96\%, 88\%, 92\%, 80\%, 95\% respectively). ${ }^{5}$ In comparison, Mysorekar et al and Young et al reported higher sensitivity (100\%).15, 16

The reasons for lower sensitivity were two false negative cases; one case was unsatisfactory on IC due to large areas of necrosis and showed squamous cell carcinoma on HPE. One case was reported negative for malignancy on IC, turned out to be squamous cell carcinoma on HPE due to sub- epithelial location of the tumor, which was missed on imprint. [Fig 5a, b] To avoid false negatives, unsatisfactory smears should never be interpreted as negative for malignancy. Multiple biopsies should be taken to improve the diagnostic accuracy. Imprint cytology has low sensitivity for sub-epithelial lesions like lymphoma, carcinoid, GIST and metastatic malignancies.

No false positive cases were reported. False positive cases can be due to reactive atypia. Caution should be exercised while reporting atypia in the presence of inflammation.

Though brush cytology has gained popularity in diagnosis of GI lesions, it is fraught with pitfalls. The biopsy forceps can obtain material deeper than the brush and touch imprints made from them provide more information, besides providing material for HPE examination. Young et al reported higher sensitivity of imprint cytology compared to the brush. 16

CONCLUSION: GI cytology is a field little explored. Imprint cytology being a simple and rapid procedure, can be adopted as a routine procedure in evaluation of various GI lesions. IC provides a method of rapid assessment of adequacy of biopsies, enabling the clinician to take repeat biopsies in the same session if necessary. To improve the sensitivity, imprints should be taken from multiple biopsies and care should be taken to identify tumor cells in areas of necrosis. Reactive atypia should be differentiated from malignancy by following strict criteria to avoid false positive results. Though imprint smears are accurate in identification of malignancy, they must be correlated with HPE for assessing depth of invasion and for typing of tumors. More studies are required to explore the potential of imprint cytology in diagnosis of various lesions in GIT as well as in other tissues. 


\section{ORIGINAL ARTICLE}

ACKNOWLEDGEMENT: We thank the Departments of Gastroenterology and Surgery for providing us samples for the study.

\section{REFERENCES:}

1. Winawer SJ, Sherlock P, Hajdu SI. The role of upper gastrointestinal endoscopy in patients with cancer. Cancer. 1976 Jan; 37(1 suppl): 440-8.

2. Bibbo M. How technology is reshaping the practice of non gynecologic cytology: frontiers of cytology symposium. Acta Cytol 2007; 51:123-52.

3. Conrad R, Prabhu SC, Cobb C, Raza A. Role of cytopathology in the diagnosis and management of gastrointestinal tract cancers. J gastrointest oncol. 2012; 3(3):285-98.

4. Kramer H, van Putten JWG, Post WJ. Oesophageal endoscopic ultrasound with fine needle aspiration improves and simplifies the staging of lung cancer. Thorax 2004; 59:596-601.

5. Cherian JV, Sivaraman R, Muthusamy AK, Jayanthi V. Carcinoma of the Esophagus in Tamil Nadu (South India):16-year Trends from a Tertiary Center. J Gastrointestin Liver Dis. September 2007;16( 3): 245-9

6. Sharma P,Misra V.A correlative study of histology and imprint cytology in diagnosis of GIT malignancies. Indian J Pathol Microbiol.1997;40(2):139-147.

7. Hamilton SR, Aaltonen LA. World Health Organization Classification of Tumours. Pathology and Genetics of Tumours of the Digestive System. Chapter 4; Lyon: IARC Press, 2000: 69-92

8. Kidambi T, Toto E, Ho N, Taft T, Hirano I. Temporal trends in the relative prevalence of dysphagia etiologies from 1999-2009.World J Gastroenterol. 2012 August 28; 18(32): 43354341.

9. Jaiswal KN, Umap PS, Jaiswal N, Shrikhande AV. Crush preparation cytology of gastroesophageal malignancies.Journal of cytol. 2005; 22(1):35-8.

10. Lu XJ, Chen ZF, Guo CL, Shao-Sen Li. Endoscopic survey of esophageal cancer in a high-risk area of China. World J Gastroenterol 2004; 10(20):2931-5.

11. Rosai J.Rosai and Ackerman's surgical pathology.9th ed.Noida; Elsevier:2009:620-4

12. Yantiss RK. Diagnostic Challenges in the Pathologic Evaluation of Barrett's Esophagus.Arch Pathol Lab Med. 2010; 134:1589-1600.

13. Balasubramanian G, Singh M, Gupta N, Gaddam S, Giacchino M, Wani SB, Moloney B, Higbee AD, Rastogi A, Bansal A, Sharma P. Prevalence and Predictors of Columnar Lined Esophagus in Gastroesophageal Reflux Disease (GERD) Patients undergoing upper endoscopy . Am J Gastroenterol. 2012. doi: 10.1038/ajg.2012.299.

14. Scott BB, Jenkins D. Gastro-oesophageal candidiasis .Gut. 1982; 23:137-9.

15. Mysorekar VV, Dandekar CP, Satyaprakash BS, Sarkar A. Role of imprint cytology in the diagnosis of gastrointestinal tract malignancies. Indian J Pathol Microbiol. 2003 Jan;46(1):3743.

16. Young JA, Hughes HE. Three year trial of endoscopic cytology of the stomach and duodenum. Gut. 1980; 21: 241-6. 


\section{ORIGINAL ARTICLE}

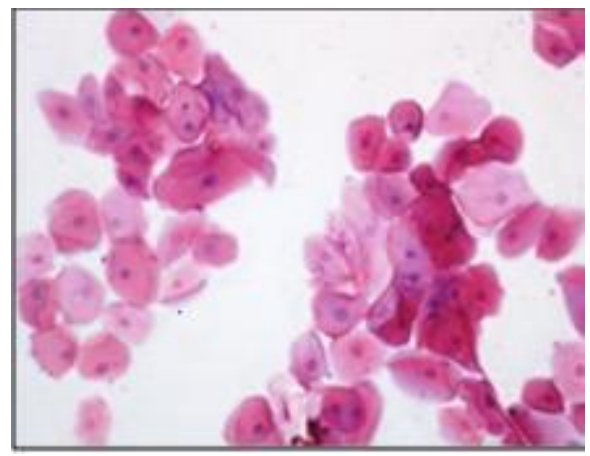

FIG 1: Imprint smear showing normal looking squamous cells [H \& E x 100]
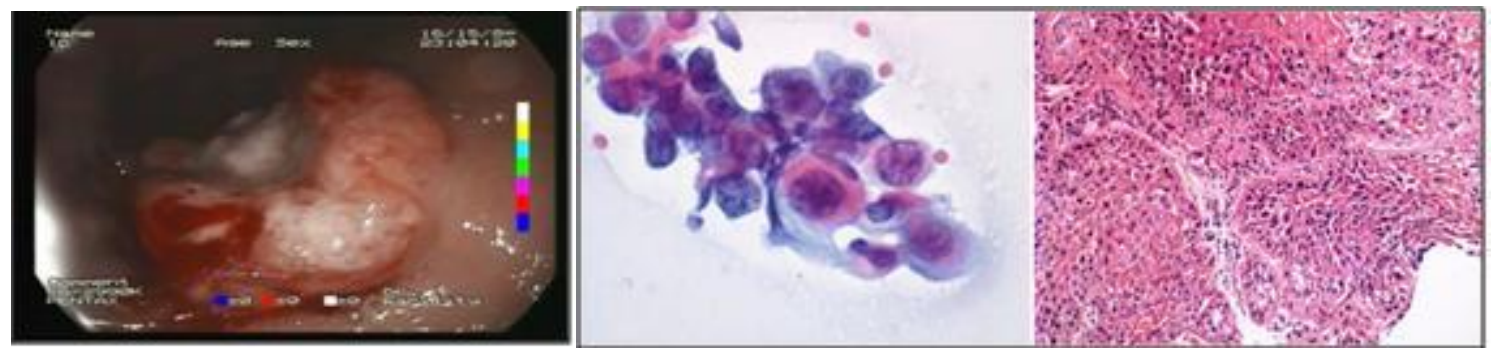

FIG 2A: Endoscopy: Proliferative growth lower end esophagus.

FIG 2B: Squamous cell carcinoma: Imprint smear showing pleomorphic squamoid cells in clusters with orangeophilia of cytoplasm [Pap x400].

FIG 2C: Squamous cell carcinoma: Tissue section showing sheets of pleomorphic squamoid cells with areas of keratinization [H\&E x 100]

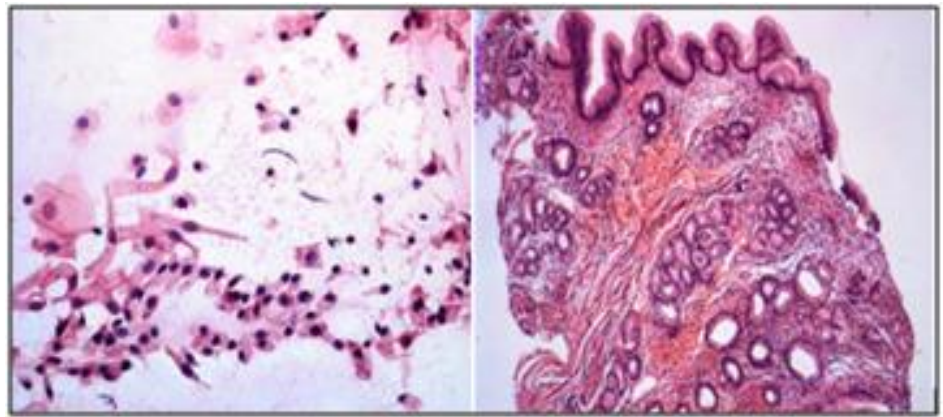

FIG 3A: Barrett's esophagus: Imprint smear showing benign columnar cells with admixed squamous cells [H \& Ex 200]

FIG 3B: Barrett's esophagus: Tissue section of the above case showing columnar epithelium overlying esophageal submucosal glands [H \& E X 200] 


\section{ORIGINAL ARTICLE}

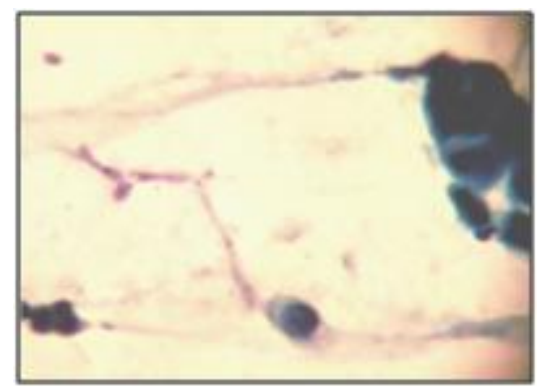

FIG 4: Imprint smear showing Candida yeast and hyphal forms [Pap x 400]

CHART 1: Comparison of sensitivity, specificity and diagnostic accuracy of IC in the present study with other studies for esophageal neoplasms
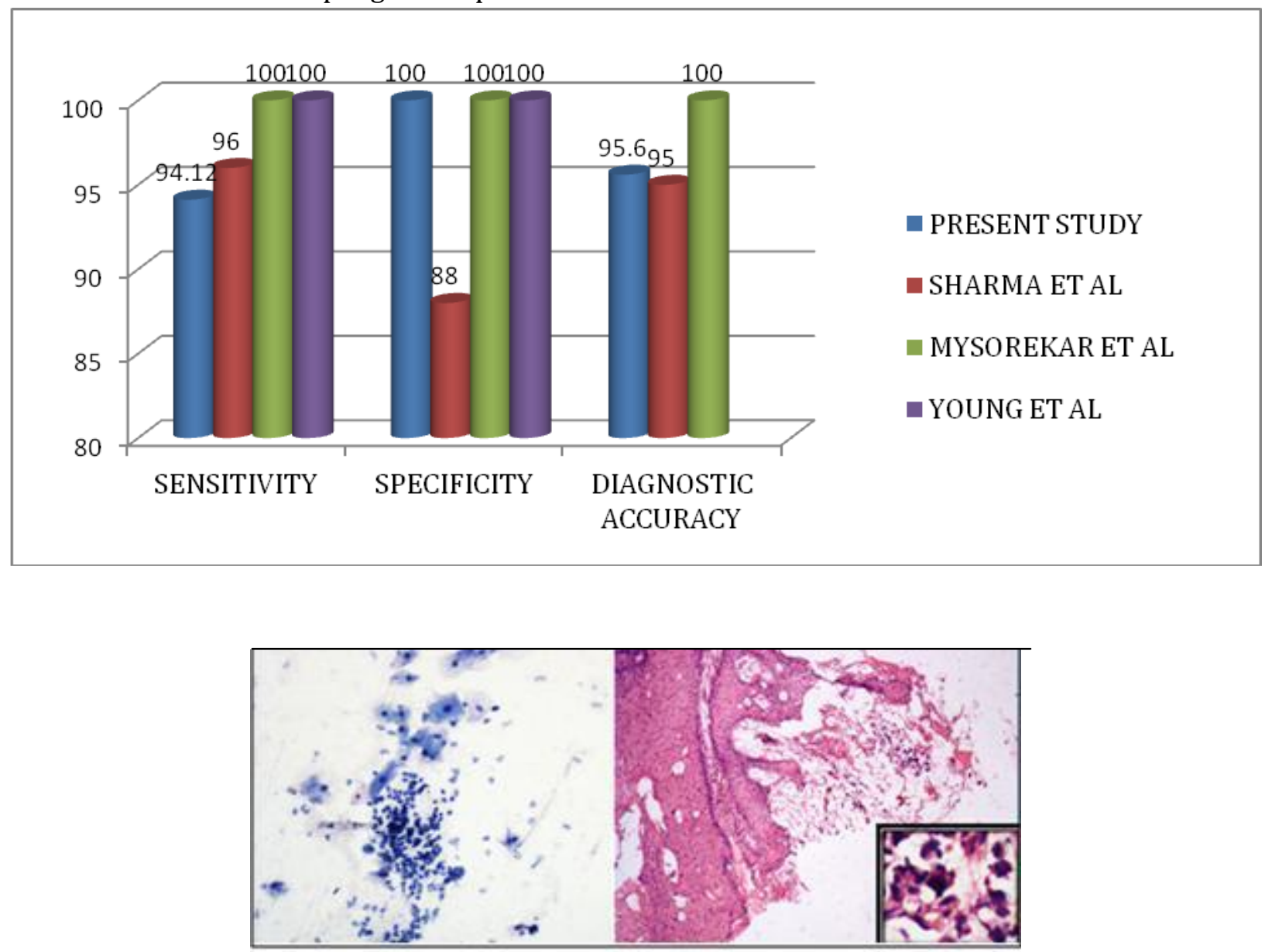

FIG 5A: False negative case: Imprint smear showing benign squamous cells with inflammatory cells in the background. [Pap x 100].

FIG 5B: Tissue section showing poorly differentiated carcinoma in lamina propria with normal overlying epithelium [H \& E x40]. Inset shows the tumor cells. 